\begin{tabular}{l|l|l|l} 
Case Reports in & $\begin{array}{l}\text { Case Rep Neurol 2010;2:24-31 } \\
\text { D01: 10.1159/000313599 }\end{array}$ & & $\begin{array}{l}\text { Published online: April 27, } 2010 \\
\text { ISSN 1662-680X } \\
\text { www.karger.com/crn }\end{array}$
\end{tabular}

\title{
Transesophageal Echocardiographically- Confirmed Pulmonary Vein Thrombosis in Association with Posterior Circulation Infarction
}

\author{
Justin A. Kinsella ${ }^{a}$ Allan J. MacCarthy ${ }^{a}$ Thomas J. Kiernan ${ }^{b}$ \\ David P. Moore ${ }^{b}$ Raymond S. McDermott ${ }^{c}$ \\ Dominick J.H. McCabe ${ }^{a, d}$ \\ Departments of a Neurology, ${ }^{b}$ Cardiology, and ${ }^{\mathrm{c} O n c o l o g y}$, The Adelaide and Meath \\ Hospital, incorporating the National Children's Hospital, Trinity College Dublin, \\ Dublin, Ireland; 'Department of Clinical Neurosciences, Royal Free Campus, UCL \\ Institute of Neurology, London, UK
}

\section{Key Words}

Pulmonary vein thrombosis - Stroke - Transesophageal echocardiography - Pancreatic adenocarcinoma

\begin{abstract}
Pulmonary venous thromboembolism has only been identified as a cause of stroke with pulmonary arteriovenous malformations/fistulae, pulmonary neoplasia, transplantation or lobectomy, and following percutaneous radiofrequency ablation of pulmonary vein ostia in patients with atrial fibrillation. A 59-year-old man presented with a posterior circulation ischemic stroke. 'Unheralded' pulmonary vein thrombosis was identified on transesophageal echocardiography as the likely etiology. He had no further cerebrovascular events after intensifying antithrombotic therapy. Twenty-eight months after initial presentation, he was diagnosed with metastatic pancreatic adenocarcinoma and died 3 months later. This report illustrates the importance of doing transesophageal echocardiography in presumed 'cardioembolic' stroke, and that potential 'pulmonary venous thromboembolic' stroke may occur in patients without traditional risk factors for venous thromboembolism. Consideration should be given to screening such patients for occult malignancy.
\end{abstract}




\begin{tabular}{l|l|l|l} 
Cose Reports in & $\begin{array}{l}\text { Case Rep Neurol 2010;2:24-31 } \\
\text { Dol: } 10.1159 / 000313599\end{array}$ & Published online: April 27, 2010 & $\begin{array}{l}\text { @ 2010 S. Karger AG, Basel } \\
\text { ISSN 1662-680X } \\
\text { www.karger.com/crn }\end{array}$ \\
\hline
\end{tabular}

\section{Case Report}

A 59-year-old, right-handed man suddenly developed lightheadedness, shimmering visual disturbance in his right visual field, nausea and vomiting with subsequent ataxia, dysarthria, left facial weakness and left upper limb numbness. He had no respiratory or cardiac symptoms and was transferred to our hospital for urgent assessment.

He had a background of mild hyperlipidemia, hypertension, migraine equivalents of later life (migraine sine cephalgia), and metal mitral valve replacement 7 years previously for mitral stenosis identified on routine echocardiography. He had had possible 'scarlet fever' as a child, but did not remember having rheumatic fever. He had recurrent posterior circulation transient ischemic attacks (TIAs) after mitral valve surgery, and aspirin and dipyridamole were empirically added to warfarin at that time. He was on aspirin $75 \mathrm{mg}$ daily, dipyridamole $100 \mathrm{mg}$ TID, warfarin (INR 2.1 six days before presentation), perindopril $4 \mathrm{mg}$ daily, and pravastatin $20 \mathrm{mg}$ daily at the time of presentation. He was a lifelong non-smoker and consumed 6 units of alcohol weekly.

Clinical examination revealed a blood pressure of $125 / 70 \mathrm{~mm} \mathrm{Hg}$, pulse rate 72 beats per minute and regular, with normal general and vascular examination otherwise. There were no clinical findings suggestive of underlying neoplasia. He had mild dysarthria and normal cranial nerves otherwise. Limb tone and power were normal, with mild incoordination in the upper limbs and right lower limb. Right upper limb reflexes were slightly brisk, with normal deep tendon reflexes otherwise, bilateral flexor plantar responses and normal sensory testing. He had gait ataxia and was falling to the left while walking, with moderate to severe impairment of heel-toe walking, and bilaterial cerebellar rebound drift.

On admission, INR was 3.0, factor VIII activity $2.07 \mathrm{IU} / \mathrm{ml}$ (normal range $0.5-2.0$ ), with normal activated protein $\mathrm{C}$ resistance, negative anticardiolipin and anti-beta II glycoprotein 1 antibodies, lupus anticoagulant, factor V Leiden, methylenetetrahydrofolate reductase and prothrombin G20210A mutation screening. Protein $\mathrm{C}$ and protein $\mathrm{S}$ were unavailable due to warfarin therapy, with normal hematological, biochemical, and auto-antibody screening otherwise. Electrocardiogram showed an incomplete right bundle branch block, but was otherwise normal. Prolonged inpatient cardiac telemetry did not reveal any arrhythmias. MRI brain (fig. 1) revealed acute right pontine infarction and longstanding cerebral small vessel disease. Urgent transesophageal echocardiogram (TEE) revealed a small patent foramen ovale on 2-dimensional imaging, with minimal left-to-right flow on color Doppler, but without definite right-to-left interatrial shunting following injection of agitated saline and modified Valsalva maneuver. There was a sessile echodensity in the proximal right superior pulmonary vein consistent with a pulmonary vein thrombosis (PVT) (fig. 2). The prosthetic mitral valve was normal, with no valvular vegetations. Doppler ultrasound of leg veins showed no deep vein thrombosis.

The patient was initially anticoagulated with intravenous heparin, with a target activated partial thromboplastin time ratio of 3.2 (range 3-3.5), and warfarin and antiplatelet therapy were held. Repeat TEE 8 days later showed resolving, but persistent thrombus in the right superior pulmonary vein (fig. 3). Thoracic CT angiography with venous phase imaging 7 days after this repeat TEE did not identify a pulmonary arteriovenous malformation or arteriovenous fistula, and the pulmonary vein thrombus was not identified on CT. Intracranial magnetic resonance angiography (MRA) showed a dominant right vertebral artery. The distal left vertebral artery was patent, the basilar artery was patent, but there was a focal narrowing of the left P1 segment of the left posterior cerebral artery consistent with either embolic or atherosclerotic stenosis, with normal intracranial arteries otherwise. Extracranial contrast-enhanced MRA was degraded by venous contamination artefact, and of insufficient quality to definitively exclude proximal extracranial vertebral stenosis. We did not proceed to intraarterial catheter angiography because the patient stabilized after the decision to commence urgent IV heparin was made.

Warfarin was recommenced when the patient clinically stabilized, aiming for a target INR of 3.5 (range: 3-4.0); i.v. heparin was stopped when his INR stabilized within the new 'therapeutic range', and he was initially discharged on warfarin monotherapy. Aspirin $75 \mathrm{mg}$ daily was empirically added at a later date because he had one further sensory TIA 29 days after initial symptom onset and because of difficulty in achieving anticoagulation targets.

Repeat TEE 12 weeks after symptom onset revealed complete resolution of the pulmonary vein thrombus, with no right to left interatrial shunting on contrast injection (not shown). The patient made an excellent recovery (modified Rankin Scale score $=0$ ), with no further cerebrovascular events over the next 22 months. 


\begin{tabular}{l|l|l|l} 
Cose Reports in & $\begin{array}{l}\text { Case Rep Neurol 2010;2:24-31 } \\
\text { D0I: 10.1159/000313599 }\end{array}$ & Published online: April 27, 2010 & $\begin{array}{l}\text { @ 2010 S. Karger AG, Basel } \\
\text { ISSN 1662-680X } \\
\text { www.karger.com/crn }\end{array}$ \\
\hline
\end{tabular}

28 months after initial presentation, he presented with a 6-month history of weight loss, abdominal discomfort and fatigue. Biochemical, radiological (abdominal ultrasound and CT), and histological investigations revealed widespread metastatic pancreatic ductal adenocarcinoma, most likely arising in the body of the pancreas with metastases to the liver. He did not have formal paraneoplastic antibody screening or repeat thrombophilia screening by his attending physician at that stage. The patient was commenced on gemcitabine and erlotinib combination chemotherapy, but died from metastatic adenocarcinoma approximately 3 months later. Postmortem examination was not performed.

\section{Discussion}

The pulmonary veins are the most proximal source of 'arterial' thromboembolism. Symptoms of pulmonary venous thrombosis are usually nonspecific, including dyspnea, cough, chest discomfort or hemoptysis, and may mimic other pulmonary disorders including pulmonary arterial thromboembolism. PVT causing TIA or stroke has only been reported in association with underlying lung neoplasia [1], previous pulmonary transplant or lobectomy $[2,3]$, pulmonary arteriovenous malformations or fistulae [4], or as a consequence of percutaneous radiofrequency ablation of pulmonary vein ostia in patients with atrial fibrillation $[5,6]$.

This case illustrates that 'unheralded' PVT may cause pulmonary thromboembolic stroke in the absence of any typical respiratory symptoms, or any of the aforementioned traditional risk factors for PVT. Factor VIII levels were very mildly elevated after presentation, and although this could have potentially increased the risk of thrombosis, the levels may only have been temporarily elevated as an acute phase response following stroke. We did not identify any other abnormalities on comprehensive thrombophilia screening, although protein $S$ and protein $C$ levels could not be tested because the patient was on warfarin.

Grau et al. prospectively studied 18 patients with recent mild or moderately severe cryptogenic ischemic stroke [7]. The authors attempted to identify PVT as a cause of embolic stroke in patients with an otherwise negative stroke workup using gadoliniumenhanced MR venography (MRV) of the pulmonary veins. This imaging technique failed to identify PVT in any of these cases, but could only visualize pulmonary veins $\geq 3 \mathrm{~mm}$ in diameter. Multiplane TEE visualizes the left atrium, left atrial appendage, left sided cardiac valves, ascending thoracic aorta, left main coronary artery, fossa ovalis and proximal pulmonary veins, in particular the left superior pulmonary vein, better than transthoracic echocardiography $[8,9]$. Our case illustrates the value of performing TEE in patients with presumed 'cardioembolic stroke', especially in association with a prosthetic heart valve. Although we did not perform simultaneous pulmonary MRV, TEE is likely to be more sensitive at identifying right superior pulmonary vein thrombus than pulmonary MRV because it allows direct visualization of the lumen and wall of the vessel. In this instance, the information obtained from TEE facilitated understanding of the most likely etiology of this patient's stroke and helped guide management.

The presence of a mitral valve replacement may have contributed to the pathogenesis of PVT by altering hemodynamics within the left atrium, and may have predisposed to pulmonary venous stasis and thrombosis in combination with the patient's other established vascular risk factors. Further TEE studies in patients with stroke in the setting of a mitral valve prosthesis are warranted to visualize the pulmonary veins to test this hypothesis in this patient subgroup. We cannot completely exclude thromboembolism from the prosthetic mitral valve prior to performance of the initial TEE causing stroke in this case. However, identification of thrombotic-like material in the right superior 
pulmonary vein, with subsequent resolution of this echodensity over time points to pulmonary venous thromboembolism in this case.

We are unaware of prior reports of pulmonary venous thromboembolic stroke in patients subsequently diagnosed with pancreatic adenocarcinoma during long-term follow-up. Venous thromboembolism in association with underlying pancreatic carcinoma is well recognized [10], and has been reported to be more common with tumors arising in the tail or body of the pancreas compared with the pancreatic head [11]. This has been postulated to be due to the longer time interval to diagnosis and subsequent greater tumor burden, and the fact that pancreatic tail and body tumors are more likely to be mucinous adenocarcinomas than tumors arising in the head of the pancreas.

Pancreatic carcinomas release prothrombotic factors, including mucin and trypsin [12], which may contribute to the risk of venous thromboembolism. Gangi et al. reviewed prior available abdominal CT imaging in patients who were subsequently diagnosed with pancreatic cancer [13]. The authors identified CT imaging findings that, in retrospect, were consistent with, or highly suspicious of a pancreatic tumor in 50\% of patients who had been scanned 2-18 months before their diagnosis was finally established; $7 \%$ of their cohort actually had abnormal imaging findings more than 18 months before their final diagnosis. Although it is possible that a 'paraneoplastic hypercoaguable state' could have predisposed to PVT in this case 28 months before the diagnosis of pancreatic cancer, the available thrombophilia screening was normal at the time of initial presentation. Because 'unheralded' thrombosis of the right superior pulmonary vein potentially causing stroke has not been previously reported, consideration should be given to screening future patients with this rare presentation for an underlying occult pancreatic malignancy. 


\begin{tabular}{l|l|l|l} 
Case Reports in & $\begin{array}{l}\text { Case Rep Neurol 2010;2:24-31 } \\
\text { D0I: 10.1159/000313599 }\end{array}$ & Published online: April 27, 2010 & $\begin{array}{l}\text { @ 2010 S. Karger AG, Basel } \\
\text { ISSN 1662-680X } \\
\text { www.karger.com/crn }\end{array}$ \\
\hline
\end{tabular}

Fig. 1. Axial MR diffusion weighted image showing acute right pontine infarction (arrow).

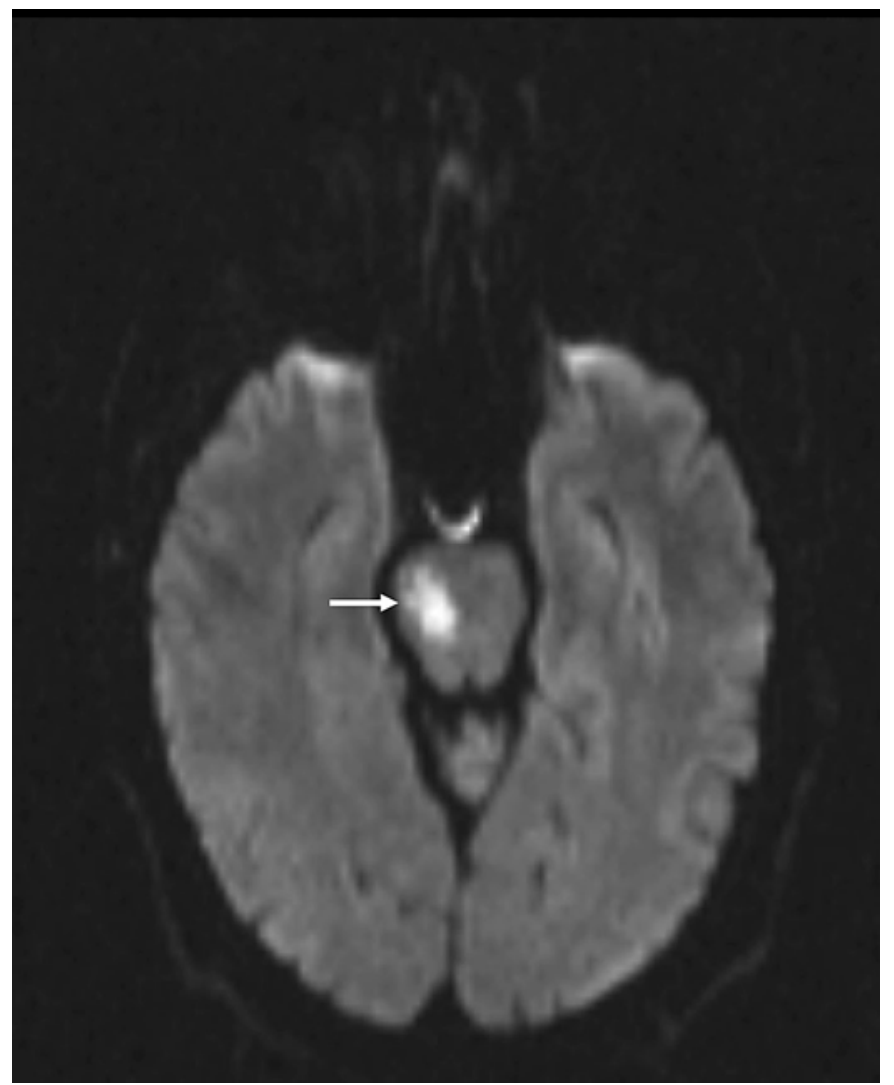




\begin{tabular}{l|l|l|l} 
Case Reports in & $\begin{array}{l}\text { Case Rep Neurol 2010;2:24-31 } \\
\text { D0I: 10.1159/000313599 }\end{array}$ & Published online: April 27, 2010 & $\begin{array}{l}\text { @ 2010 S. Karger AG, Basel } \\
\text { ISSN 1662-680X } \\
\text { www.karger.com/crn }\end{array}$ \\
\hline
\end{tabular}

Fig. 2. Baseline 2D TEE demonstrating mobile echogenic thrombus within right superior pulmonary vein. $\mathrm{RSPV}=$ right superior pulmonary vein; $\mathrm{LA}=$ left atrium; THROMBUS = pulmonary vein thrombus.

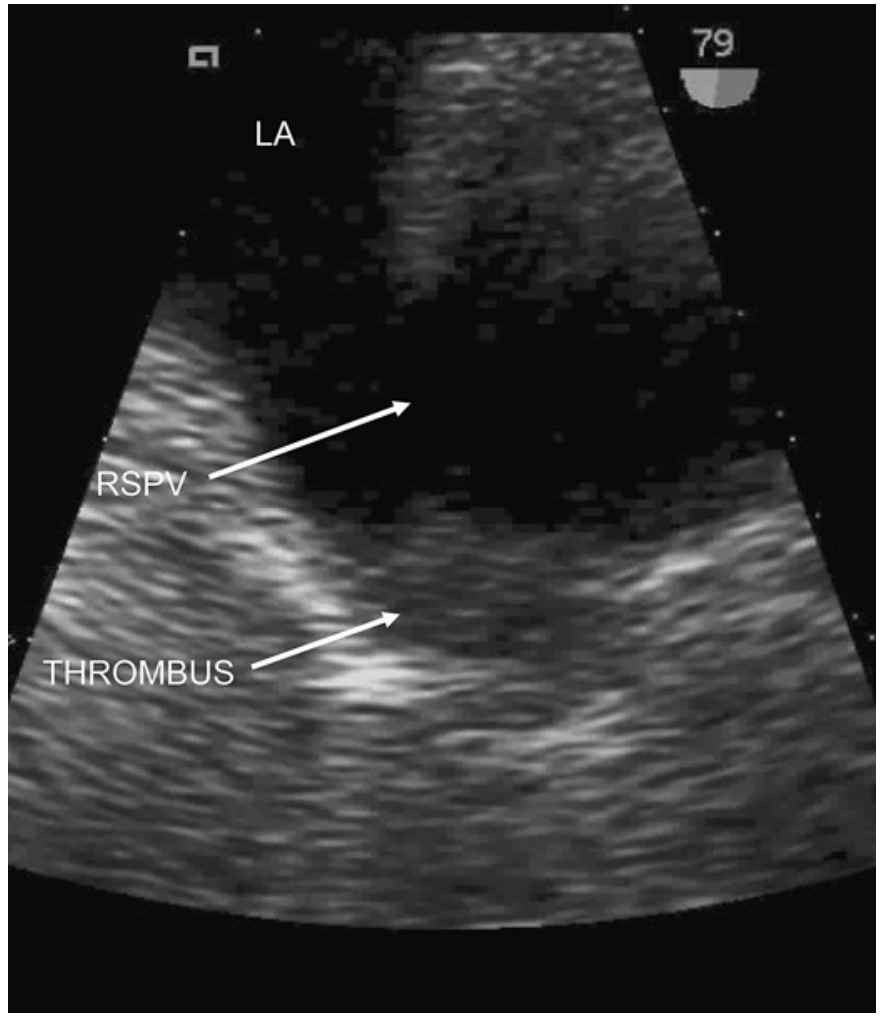




\begin{tabular}{l|l|l|l} 
Case Reports in & $\begin{array}{l}\text { Case Rep Neurol 2010;2:24-31 } \\
\text { D0I: 10.1159/000313599 }\end{array}$ & Published online: April 27, 2010 & $\begin{array}{l}\text { @ 2010 S. Karger AG, Basel } \\
\text { ISSN 1662-680X } \\
\text { www.karger.com/crn }\end{array}$ \\
\hline
\end{tabular}

Fig. 3. Repeat TEE image 8 days later demonstrating partial resolution of the PVT. RSPV = right superior pulmonary vein; LA = left atrium; THROMBUS = pulmonary vein thrombus.

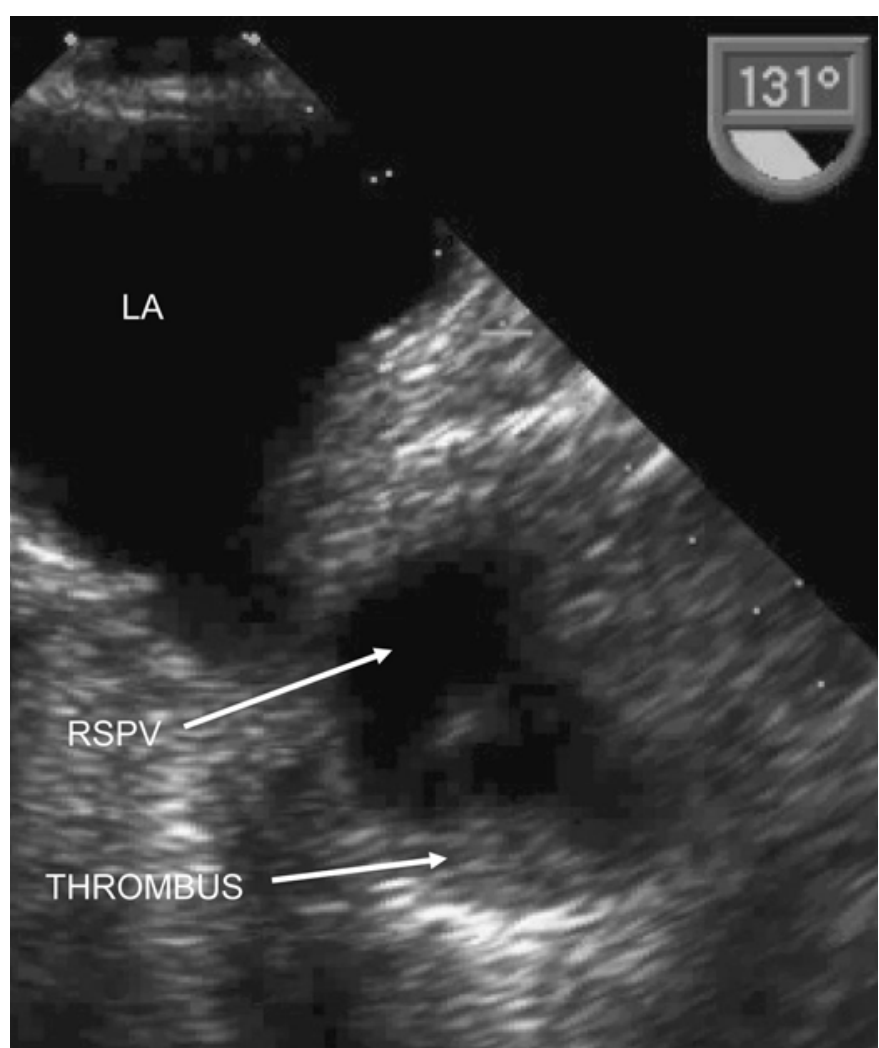




\begin{tabular}{l|l|l|l} 
Cose Reports in & $\begin{array}{l}\text { Case Rep Neurol 2010;2:24-31 } \\
\text { D01: 10.1159/000313599 }\end{array}$ & Published online: April 27, 2010 & $\begin{array}{l}\text { ○ 2010 S. Karger AG, Basel } \\
\text { ISSN 1662-680X } \\
\text { www.karger.com/crn }\end{array}$ \\
\hline
\end{tabular}

\section{References}

1 Schwalm S, Ward RP, Spencer KT: Transient ischemic attack in a patient with pulmonary vein thrombosis after left upper lobectomy for squamous cell lung cancer. J Am Soc Echocardiogr 2004;17:487-488.

-2 Nagahiro I, Horton M, Wilson M, Bennetts J, Spratt P, Glanville AR: Pulmonary vein thrombosis treated successfully by thrombectomy after bilateral sequential lung transplantation: report of a case. Surg Today 2003;33:282-284.

-3 Reilly MP, Plappert TJ, Wiegers SE: Cerebrovascular emboli related to pulmonary venous thrombosis after lung transplantation. J Am Soc Echocardiogr 1998;11:299-302.

$\checkmark 4$ Cohen R, Cabanes L, Burckel C, Duboc D, Touze E: Pulmonary arteriovenous fistulae thrombosis responsible for recurrent stroke. J Neurol Neurosurg Psychiatry 2006;77:707-708.

5 Ghaye B, Szapiro D, Dacher JN, Rodriguez LM, Timmermans C, Devillers D, Dondelinger RF: Percutaneous ablation for atrial fibrillation: the role of crosssectional imaging. Radiographics 2003;23(Spec No):S19-S33.

6 Wnuk-Wojnar AM, Trusz-Gluza M, Czerwinski C, Wozniak-Skowerska I, Szydlo K, Hoffman A, Nowak S, Wita K, Konarska-Kuszewska E, Krauze J, RybickaMusialik A, Drzewiecka-Gerber A: Circumferential pulmonary vein RF ablation in the treatment of atrial fibrillation: 3-year experience of one centre. Kardiol Pol 2005;63:362-370.

7 Grau AJ, Schoenberg SO, Lichy C, Buggle F, Bock M, Hacke W: Lack of evidence for pulmonary venous thrombosis in cryptogenic stroke: a magnetic resonance angiography study. Stroke 2002;33:1416-1419.

-8 Ascione L, Granata G, Accadia M, Marasco G, Santangelo R, Tuccillo B: Ultrasonography in embolic stroke: the complementary role of transthoracic and transesophageal echocardiography in a case of systemic embolism by tumor invasion of the pulmonary veins in a patient with unknown malignancy involving the lung. Eur J Echocardiogr 2004;5:304-307.

-9 Warner JG Jr, Nomeir AM, Salim M, Kitzman DW: A prospective, randomized, blinded comparison of multiplane and biplane transesophageal echocardiographic techniques. J Am Soc Echocardiogr 1996;9:865-873.

10 Miller JR, Baggenstoss AH, Comfort MW: Carcinoma of the pancreas. Effect of histological type and grade of malignancy on its behaviour. Cancer 1951;4:233241.

11 Blom JW, Osanto S, Rosendaal FR: High risk of venous thrombosis in patients with pancreatic cancer: a cohort study of 202 patients. Eur J Cancer 2006;42:410 414.

12 Bick RL: Coagulation abnormalities in malignancy: a review. Semin Thromb Hemost 1992;18:353-372.

13 Gangi S, Fletcher JG, Nathan MA, Christensen JA, Harmsen WS, Crownhart BS, Chari ST: Time interval between abnormalities seen on CT and the clinical diagnosis of pancreatic cancer: retrospective review of CT scans obtained before diagnosis. AJR Am J Roentgenol 2004;182:897-903. 